\title{
A novel strategy for tailoring Cobalt/Titanium Dioxide Hollow Spheres for hydrogen production
}

\author{
Reda M Mohamed ${ }^{1,2 *}$, Mohammad W Kadi ${ }^{1}$ and Ibrahreem A Mkhalid ${ }^{1}$ \\ ${ }^{1}$ Department of Chemistry, Faculty of Science, King Abdulaziz University, P.O. Box 80203, Jeddah 21589, Kingdom of Saudi Arabia \\ ${ }^{2}$ Advanced Materials Department, Central Metallurgical R\&D Institute, CMRDI, P.O. Box 87, Helwan, Cairo 11421, Egypt
}

\begin{abstract}
Titanium dioxide absorbs light in the ultraviolet region. Shifting of the absorption from UV to visible light is very important to attain high efficiency. In this paper this was achieved by incorporation of cobalt into the titanium dioxide lattice of cobalt/titanium dioxide hollow spheres. Titanium dioxide hollow sphere and cobalt/titanium dioxide hollow sphere were prepared by a hydrothermal method in the presence of cyclohexylamine as a surfactant. For comparison purposes, titanium dioxide nanoparticles and cobalt/titanium dioxide nanoparticles were prepared by the same method in absence of the surfactant. The prepared materials were characterized by many techniques. The photocatalytic activity of cobalt/titanium dioxide hollow spheres is better than titanium dioxide hollow spheres, cobalt/ titanium dioxide nanoparticles and titanium dioxide nanoparticles for hydrogen production by $1.25,3.3$ and 33.3 times, respectively. In addition, cobalt/titanium dioxide hollow spheres exhibit photocatalytic stability for hydrogen production which enable many time reuses of the photocatalyst.
\end{abstract}

\section{Introduction}

Photocatalysis has attracted interest in many fields of scientific research and industrial applications. In photocatalysis, a catalyst is used in reactions under illumination of ultraviolet (uv) or visible radiation. The use of visible radiation allows conducting reactions in environmentally friendly fashion with no need to energy from other sources. Scientists are interested in designing catalysts with band energy that fall within the visible frequency. Other required properties in catalysts include nontoxicity, stability, possible reuse, ease of separation, favorable magnetic and electric properties along with other characteristics depending on the application required.

$\mathrm{TiO}_{2}$ is widely used photocatalyst as it possesses properties that include chemical stability, nontoxicity, possible reuse, possible incorporation in other materials, and favorable physical properties. However its wide band gab $(\mathrm{Eg}=3.2 \mathrm{eV})$ makes it active when used in reactions that involve uv light which constitute about $3 \%-5 \%$ of the solar spectrum; for this, researchers always try to manipulate its structure to narrow the band gab which in turn makes the derived material active in the natural or artificial sunlight [1].

$\mathrm{TiO}_{2}$ hollow spheres have a structure that attracted attention. Scientists developed Many approaches to synthesize $\mathrm{TiO}_{2}$ hollow spheres and this area of research is still active [2] Yan, et al. fabricated $\mathrm{TiO}_{2}$ hollow spheres through a template-free solvothermal route and applied it to rhodamine degradation [3]. Eiden and Maret reported the synthesis of $\mathrm{TiO}_{2}$ hollow spheres consisting exclusively of crystalline rutile structure [4]. Wang, et al. prepared anatase titania hollow micro spheres using styrene-acrylic acid copolymer latex particles as template and showed characterization of these spheres [5]. Lei, et al. prepared $\mathrm{TiO}_{2}$ hollow spheres via a facile hydrothermal method without the use of any template agent and demonstrated improved performance in dyesensitized solar cells [6]. Zhang, et al. reported Controlled fabrication of nanosized $\mathrm{TiO}_{2}$ hollow sphere particles via acid catalytic hydrolysis/ hydrothermal treatment and tested the catalyst on phenol removal
[7]. Fing, et al. reported catalyst-free hydrothermal method for the preparation of titania hollow spheres [8]. Lin, et al. reported Synthesis of hollow spherical $\mathrm{TiO}_{2}$ for dye-sensitized solar cells and demonstrated the enhanced light harvesting efficiency of the structure [9]. Wang, et al. reported the synthesis of $\mathrm{TiO}_{2}$ hollow microspheres with mesoporous surface via a facile template-assisted solvothermal reaction and demonstrated a superior adsorption performance for dye removal [10]. Ye, et al. reported hydrothermal synthesis of $\mathrm{TiO}_{2}$ hollow microspheres for the photocatalytic degradation of 4-chloronitrobenzene [11].

Preparations that include variety of crystal structures and various dopants on the $\mathrm{TiO}_{2}$ hollow spheres are also of interest. Zhang, et al. prepared hollow core/shell $\mathrm{CeO}_{2} @ \mathrm{TiO}_{2}$ photocatalysts via precipitationco-hydrothermal method and applied it in the removal of rhodamine B as a model dye pollutants [12]. Fang, et al. prepared hollow carbondoped titania composite spheres through a template-assisted method and illustrated its potential application prospect in the development of electrophoretic ink [13]. Qu, et al. prepared $\mathrm{TiO}_{2}$ and $\mathrm{TiO}_{2}: \mathrm{Gd}^{3+}$ hollow spheres with Gd doping with the assistance of the carbon sphere templates and demonstrated enhanced photocatalytic activity [14]. Liu, et al. solvothermally synthesized hybrid $\mathrm{TiO}_{2}$ hollow spheres using tetrabutyl titanate and hydrated metal sulfates as soft templates and reported excellent efficiency and durability in photo-decomposition of methyl orange (MO) under visible-light irradiation [15]. Geng, et al. reported a facile route for the controllable design of fluorinedoped carbon-treated $\mathrm{TiO}_{2}$ hollow spheres with mesoporous shells

${ }^{\star}$ Correspondence to: Mohamed RM, Department of Chemistry, Faculty of Science, King Abdulaziz University, P.O. Box 80203, Jeddah 21589, Kingdom of Saudi Arabia, Email: redama123@yahoo.com

Key words: hollow sphere, nanoparticles, TiO2, Cobalt, visible light, hydrogen production

Received: July 20, 2019; Accepted: July 31, 2019; Published: August 05, 2019 
for improved lithium storage [16]. Zhang, et al. reported preparation carbon coated $\mathrm{TiO}_{2}$ hollow composite spheres with enhanced visible photocatalytic performance in the degradation of rhodamine $\mathrm{B}$ dye [17]. Cho, et al. reported preparation and photocatalytic activity of nitrogen-doped $\mathrm{TiO}_{2}$ hollow nanospheres [18]. Wang, et al. reported one-step template-free fabrication of mesoporous $\mathrm{ZnO} / \mathrm{TiO}_{2}$ hollow microspheres and demonstrated the enhanced photocatalytic activity on degradation of methyl orange [19]. Tang, et al. reported $\alpha-\mathrm{Fe}_{2} \mathrm{O}_{3} /$ $\mathrm{TiO}_{2}$ composite hollow spheres synthesis by a template-assisted precipitation reaction and the activity of the catalyst was tested via the photocatalytic decolorization of $\mathrm{RhB}$ aqueous solution [20]. $\mathrm{Li}$, et al. synthesized $\mathrm{WO}_{3} / \mathrm{TiO}_{2}$ composite, hollow-sphere photocatalyst using a template method and demonstrated improved photocatalytic activity [21]. Chattopadhyay, et al. studied hydrogen production by the application of tin doped titania hollow spheres [22]. Zhang, et al. developed an in-situ synthesis of c-doped titania hollow spheres with high photoctalytic activity [23].

In an effort to produce clean and environmentally friendly energy, scientists showed great interest in the production of hydrogen from water splitting using various materials $[24,25] . \mathrm{TiO}_{2}$ is important material in this area because of its aforementioned properties. Researchers try to manipulate this material's properties to enhance its ability in the water splitting reaction. Scientists synthesized materials of various crystal structures and different morphologies for hydrogen production [26-30]. Doping with various metals and non-metals is an important way to narrow the band gap and attain good properties [3136]. Method of synthesis of a material could also impact the properties of the product [37].

In this paper we report the synthesis of a new Co doped $\mathrm{TiO}_{2}$ hollow spheres through the hydrothermal method in which cyclohexamine was used for the first time as a template and we apply this material in $\mathrm{H}_{2}$ production reaction.

\section{Experimental}

\section{Preparation of photocatalysts}

Cobalt $/ \mathrm{TiO}_{2}$ hollow spheres (Co/THS) were prepared by a hydrothermal method in which $8.0 \mathrm{~g}$ of tetrabutyl titanate and 1.5 $\mathrm{g}$ cobalt nitrate hexahydrate were dissolved in a mixed solvent $(40$ $\mathrm{mL}$ absolute ethanol $+3 \mathrm{~mL}$ of distilled water $+0.3 \mathrm{~mL} 1 \mathrm{M} \mathrm{HNO}$ ) the mixture was magnetically stirred for $30 \mathrm{~min}$ to allow complete dissolution. $0.3 \mathrm{~g}$ of cyclohexylamine was added and the solution was further stirred for $30 \mathrm{~min}$. The mixture was transferred into Teflon-lined stainless steel autoclave, which was sealed and maintained at $80{ }^{\circ} \mathrm{C}$ for $24 \mathrm{~h}$ after which the autoclave was left to cool to room temperature. The product was filtered and washed with distilled water then ethanol for several times, dried in vacuum at $80{ }^{\circ} \mathrm{C}$ for $10 \mathrm{~h}$. $\mathrm{TiO}_{2}$ hollow spheres (THS) were synthesized in the same fashion except in the absence of cobalt nitrate hexahydrate.

For comparison purposes Cobalt/ $\mathrm{TiO}_{2}$ nanoparticles $(\mathrm{Co} / \mathrm{TN})$ and $\mathrm{TiO}_{2}$ nanoparticles (TN) were prepared by hydrothermal method. Co/ TN was synthesized by dissolving $8.0 \mathrm{~g}$ of tetrabutyl titanate and 1.5 g cobalt nitrate hexahydrate in a mixed solvent composed of $40 \mathrm{~mL}$ absolute ethanol, $3 \mathrm{~mL}$ of distilled water and $0.3 \mathrm{~mL} 1 \mathrm{M} \mathrm{HNO}_{3}$ under magnetic stirring for $30 \mathrm{~min}$. The mixture was transferred into Teflonlined stainless steel autoclave, which was sealed and maintained at $80^{\circ} \mathrm{C}$ for $24 \mathrm{~h}$. The autoclave was left to cool down to room temperature and the product was filtered and washed with distilled water then ethanol for several times, dried in vacuum at $80^{\circ} \mathrm{C}$ for $10 \mathrm{~h}$. $\mathrm{TiO}_{2}$ nanoparticles were synthesized following the same procedure in the absence of cobalt nitrate hexahydrate.

\section{Characterization}

In order to obtain morphological structure, the material of interest was suspended in ethanol and ultrasonicated for $30 \mathrm{~m}$. portion of the suspension was dried on a carbon coated copper grid and loaded into a JEOL-JEM-1230 transmission electron microscope (TEM). Surface area was obtained from $\mathrm{N}_{2}$-adsorption measurements using a Nova 2000 series Chromatech apparatus at $77 \mathrm{~K}$. the crystalline phase of the four composites was determined using Bruker axis D8 with $\mathrm{Cu}$ Ka radiation $(\lambda=1.540 \AA)$ at room temperature. A Thermo Scientific $\mathrm{K}$-ALPHA spectrometer was utilized to obtain X-ray photoelectron spectroscopy (XPS) measurements. Uv-visible diffuse reflectance spectra (UV-Vis-DRS) was exploited to obtain band gap information utilizing a UV-Vis-NIR spectrophotometer (V-570, Jasco, Japan) at room temperature. Absorption was measured over 200-800 nm range. A Shimadzu RF-5301 fluorescence spectrophotometer was used to record photoluminescence emission spectra (PL).

\section{Photo-catalytic tests}

An important application in which the synthesized catalyst can be used is hydrogen production from water splitting. In the experimental setup a known weight of the photocatalyst was added into $450 \mathrm{~mL}$ aqueous solution containing $10 \mathrm{vol} \%$ methanol as a scavenger. The reaction system was sealed and the experiments were conducted at room temperature and atmospheric pressure. The heat from the lamp was prevented from affecting the reaction by placing a jacketed cooler made of quartz between the reactor and lamp. A dispersion using an ultrasonic cleaner at $100 \mathrm{~W}$ for $15 \mathrm{~min}$ was carried out. The slurry was aerated by $\mathrm{N}_{2}$ for $30 \mathrm{~min}$ and irradiated by visible light generated from $500 \mathrm{~W}$ Xenon lamp under continuous stirring. The evolved hydrogen gas generated from the reaction was analyzed by Agilent GC 7890 A gas chromatography system using $\mathrm{N}_{2}$ as carrier gas. Blank reactions with illumination in the absence of the photocatalyst and with photocatalyst in the dark were carried out. Both cases yielded no evolution of hydrogen gas.

\section{Results and discussion}

\section{Characterizations of materials}

Figure 1 shows XRD patterns of the four synthesized composites, $\mathrm{TN}, \mathrm{Co} / \mathrm{TN}, \mathrm{THS}$, and $\mathrm{Co} / \mathrm{THS}$. The patterns reveal pure $\mathrm{TiO}_{2}$ anatase phase in all four composites with no peaks of pure cobalt or cobalt oxides which could be explained by low percentage of the cobalt present. The patterns also show s shift to right in peaks of $\mathrm{Co} / \mathrm{TN}$, and $\mathrm{Co} / \mathrm{THS}$ which means incorporation of the cobalt ions within the titanium dioxide lattice. The crystallite sizes of TN, Co/TN, THS, and Co/THS are 22, 18, 14, $10 \mathrm{~nm}$ respectively as calculated by the Scherrer formula. It is clear that cobalt doping results in a decrease of crystallite and hollow spheres sizes.

Figure 2 shows TEM images of TN, Co/TN, THS, and Co/THS samples. Co/TN and TN are spherical in shape with sizes of 130 and $160 \mathrm{~nm}$, respectively. However, Co/THS, and THS are hollow spherical in shape with shell thicknesses of 15-35 and 20-45 nm, respectively and core diameter of 190 and $240 \mathrm{~nm}$, respectively. This reveals that the addition of cobalt ion decreases size of $\mathrm{Co} / \mathrm{THS}$ and $\mathrm{Co} / \mathrm{TN}$ samples.

Figure 3 shows XPS spectra of Co2p species for the Co/THS sample. It shows two peaks for Co $2 \mathrm{p}_{1 / 2}$ and Co2 $\mathrm{p}_{3 / 2}$ at 794.9 and 779.7 


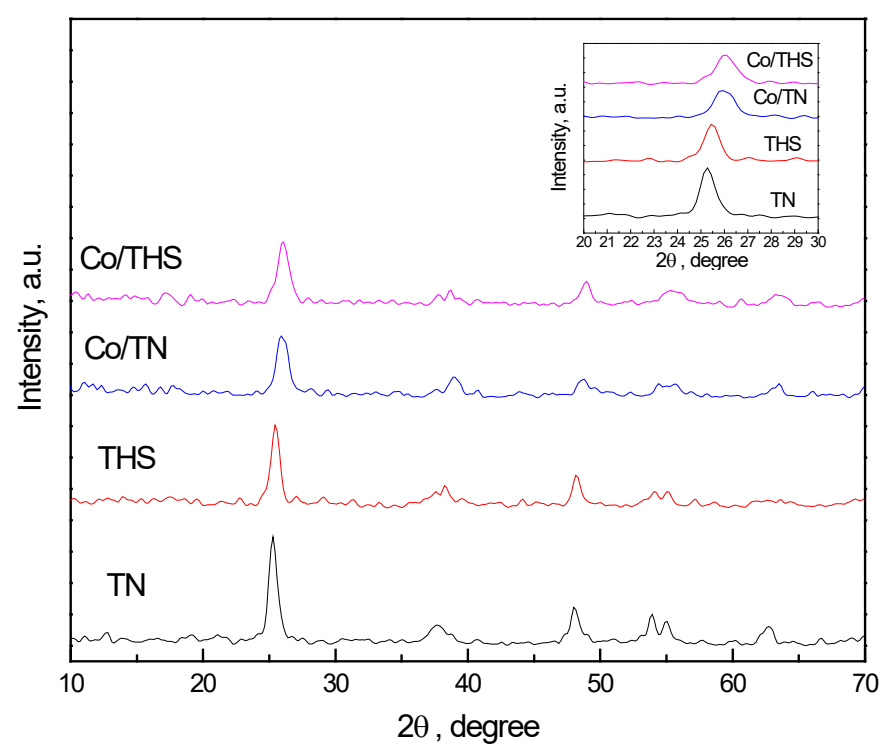

Figure 1. XRD patterns of TN, $\mathrm{Co} / \mathrm{TN}$, THS, and $\mathrm{Co} / \mathrm{THS}$ samples

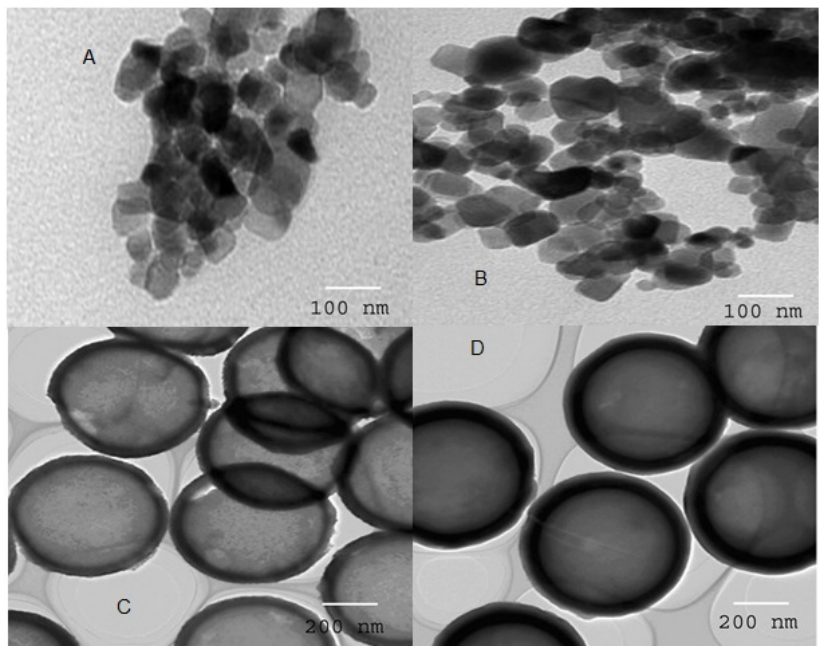

Figure 2. TEM images of (A)TN, (B) Co/TN, (C)THS, and (D) Co/THS samples

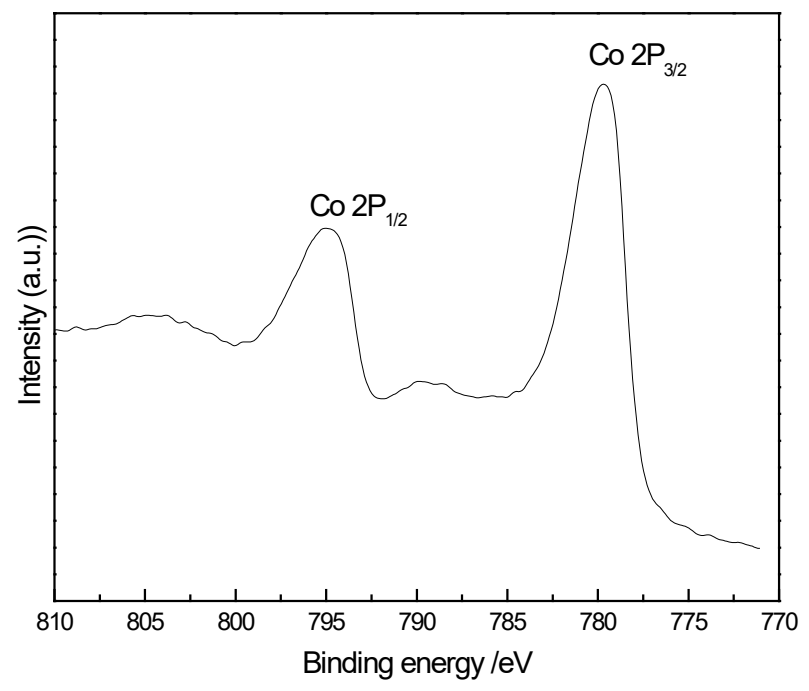

Figure 3. XPS spectra of Co $2 p$ for Co/THS sample
$\mathrm{eV}$, respectively confirming the cobalt ion $\left(\mathrm{Co}^{2+}\right.$ ion $)$ and that it is incorporated into $\mathrm{TiO}_{2}$ lattice.

Adsorption-desorption isotherms of TN (A), Co/TN (B), THS (C), and Co/THS (D) samples are shown in Figure 4. TN and Co/TN have an isotherm of type II. While THS and Co/THS show an isotherm of type IV. This is interpreted as that samples THS and Co/THS have mesoporous materials.

Pore size distribution of Co/THS is shown in Figure 5. It shows very narrow distribution around $1.9 \mathrm{~nm}$ indicating that hollow sphere samples may have a high surface area. The specific surface area of TN, Co/TN, THS, and Co/THS samples was measured by Nova 2000 resulting in values of $70,80,140$ and $155 \mathrm{~m}^{2} / \mathrm{g}$ respectively. Therefore, the hollow sphere structure increases BET surface area of titanium dioxide. These results show that there are two factors affecting the photocatalytic activity of titanium dioxide, namely the higher surface area due to hollow spherical structure and the presence of doped cobalt ion.

UV-Vis spectra of TN, Co/TN, THS, and Co/THS samples (Figure 6) reveal a red shift of absorption edges of titanium dioxide toward higher wavelengths going from nanoparticles to hollow spherical structure and also by presence of cobalt ion in the titanium dioxide lattice. The values of band gap energy of TN, Co/TN, THS, and Co/ THS samples calculated from their respective UV-Vis spectra were 3.2, $3.01,2.89$ and $2.72 \mathrm{eV}$ respectively, Showing narrowing in the band gap, hence more efficiency toward visible light photocatalysis.

$\mathrm{Pl}$ spectra of $\mathrm{TN}, \mathrm{Co} / \mathrm{TN}, \mathrm{THS}$, and $\mathrm{Co} / \mathrm{THS}$ samples (Figure7) show peak intensity decrease in the following order $\mathrm{TN}>\mathrm{Co} / \mathrm{TN}>$ THS $>\mathrm{Co} / \mathrm{THS}$ which again shows that the red shift because the change of phase of titanium dioxide from nanoparticles to hollow spheres also because of the incorporation of the cobalt ion into titanium dioxide lattice. The values of band gap energy of TN, Co/TN, THS, and Co/ THS samples calculated from their Pl emission spectra were 3.2, 3.02, 2.88 and $2.71 \mathrm{eV}$ respectively confirming data observed from the UVVis spectra.

\section{Evolution of photocatalytic performance}

Type of the photocatalyst, dose of the Co/THS photocatalyst, Recycling and reuse of Co/THS were studied to measure the photocatalytic performance for hydrogen production under visible light conditions.

Effect of type of photocatalyst on amount of hydrogen evolution was studied under the following conditions: light source is $500 \mathrm{~W} \mathrm{Xe}$ lamp; reaction time is $4 \mathrm{~h}$; dose of photocatalyst is $0.8 \mathrm{~g} / \mathrm{L}$; volume of aqueous solution is $450 \mathrm{~mL}$. Figure 8 shows the effect of type of photocatalyst on amount of hydrogen evolution. TN sample almost has no photocatalytic activity, as TN absorbs in the UV region and reaction was carried out under visible light. Performance of $\mathrm{Co} / \mathrm{TN}$ sample for hydrogen evolution was increased from 6 to $60 \mu \mathrm{mol}$, respectively, due to decrease band gap of TN from 3.2 to $3.01 \mathrm{eV}$ by cobalt doping. We observed that photocatalytic performance of THS sample for hydrogen evolution was increased from 6 to $160 \mu \mathrm{mol}$, respectively, due changing phase of titanium dioxide from nanoparticles to hollow spherical structure. Also, the pphotocatalytic performance of $\mathrm{Co} / \mathrm{THS}$ sample for hydrogen evolution was increased from 160 to $200 \mu \mathrm{mol}$ by cobalt doping. Therefore, morphology of titanium dioxide affects the photocatalytic performance along with doping of cobalt ions.

Effect of dose of Co/THS photocatalyst on amount of hydrogen evolution was studied under the following conditions: light source is 

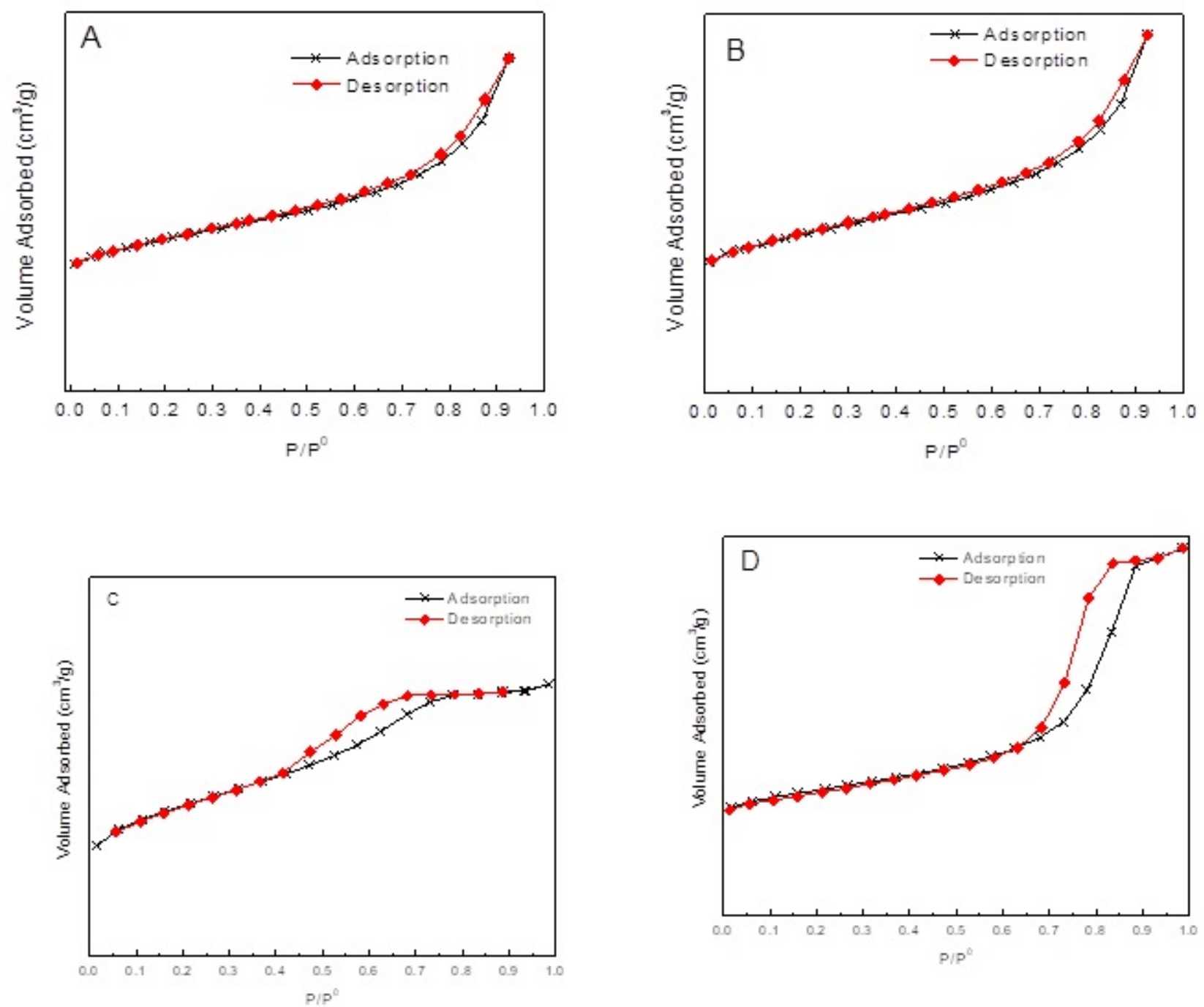

Figure 4. Adsorption-desorption isotherms of (A)TN, (B) Co/TN, (C)THS, and (D) Co/THS samples

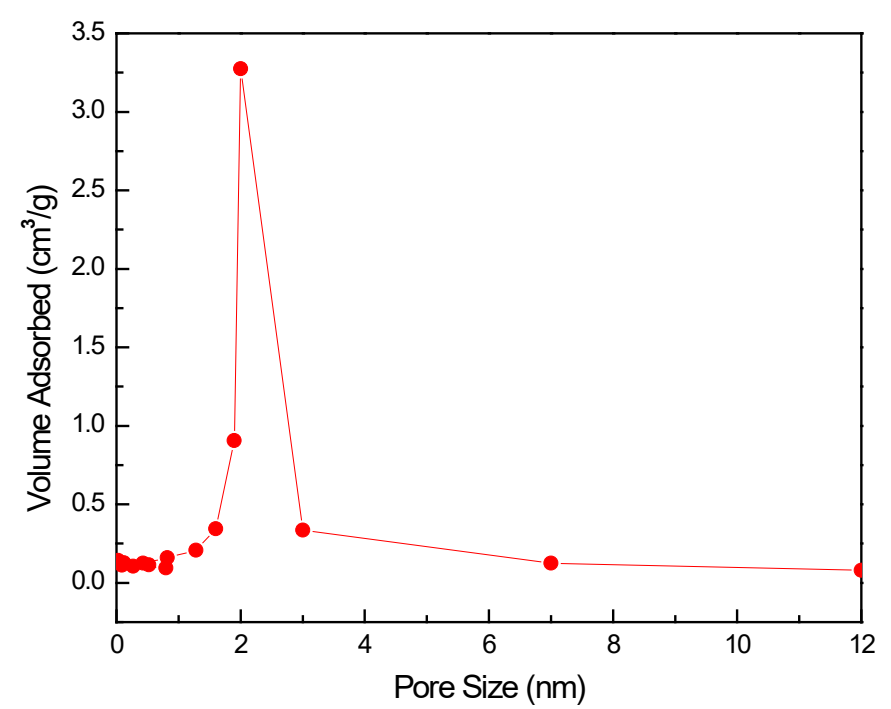

Figure 5. Pore size distribution of $\mathrm{Co} / \mathrm{THS}$ sample

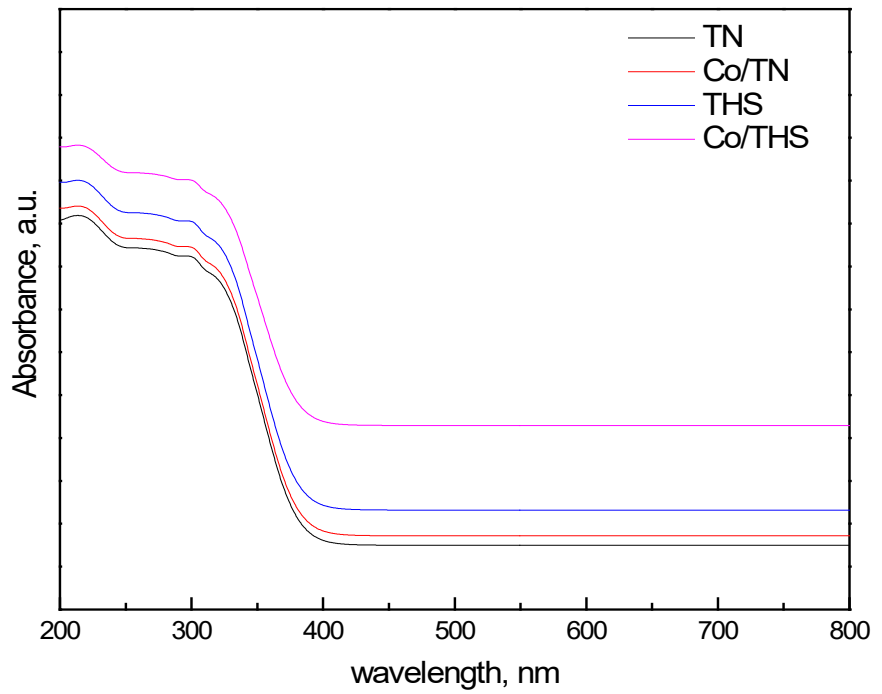

Figure 6. UV-Vis spectra of TN, $\mathrm{Co} / \mathrm{TN}$, THS, and $\mathrm{Co} / \mathrm{THS}$ samples 
$500 \mathrm{~W}$ Xe lamp; reaction time is $4 \mathrm{~h}$; dose of photocatalyst is changed from 0.4 to $2.0 \mathrm{~g} / \mathrm{L}$; volume of aqueous solution is $450 \mathrm{~mL}$. Figure 9 shows effect of dose of $\mathrm{Co} / \mathrm{THS}$ photocatalyst on amount of hydrogen evolution. Hydrogen evolution increased from 150 to $250 \mu$ mol by increased dose of Co/THS photocatalyst from 0.4 to $1.6 \mathrm{~g} / \mathrm{L}$, respectively. This could be explained by the increase in number of available sites for photocatalytic reaction as the dose increases resulting in more photocatalytic activity. Upon increasing the dose of photocatalyst above $1.6 \mathrm{~g} / \mathrm{L}$ the amount of hydrogen evaluation drops to $190 \mu \mathrm{mol}$. This may be resulting from hindrance of light penetration due to high concentration of photocatalysts particles in the reaction solution.

Recycling and reuse of Co/THS photocatalyst on amount of hydrogen evaluation was studied under the following conditions: light source is $500 \mathrm{~W}$ Xe lamp; reaction time is $4 \mathrm{~h}$; dose of photocatalyst is $1.6 \mathrm{~g} / \mathrm{L}$; volume of aqueous solution is $450 \mathrm{~mL}$. Figure 10 shows Recycling and reuse of $\mathrm{Co} / \mathrm{THS}$ photocatalyst on amount of hydrogen

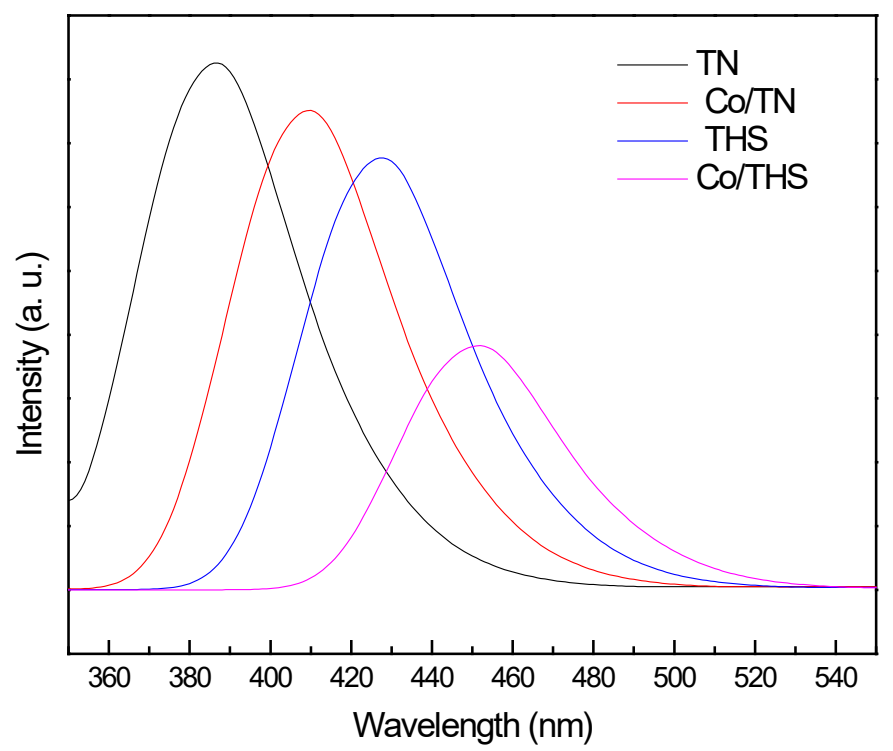

Figure 7. $\mathrm{Pl}$ spectra of $\mathrm{TN}, \mathrm{Co} / \mathrm{TN}$, THS, and $\mathrm{Co} / \mathrm{THS}$ samples

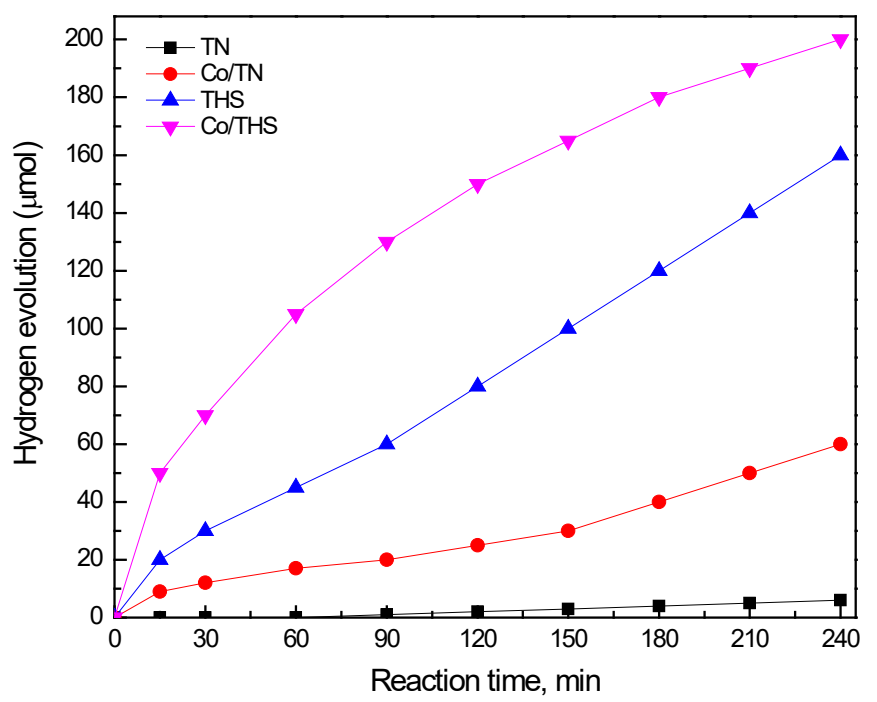

Figure 8. Effect of type of photocatalyst on amount of hydrogen evaluation

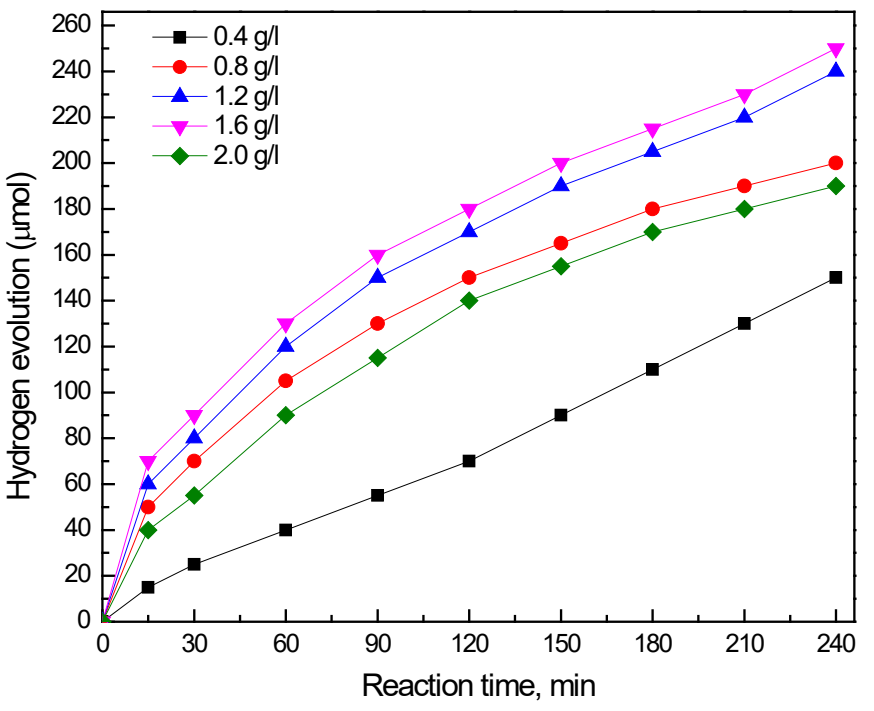

Figure 9. Effect of dose of $\mathrm{Co}$ /THS photocatalyst on amount of hydrogen evaluation

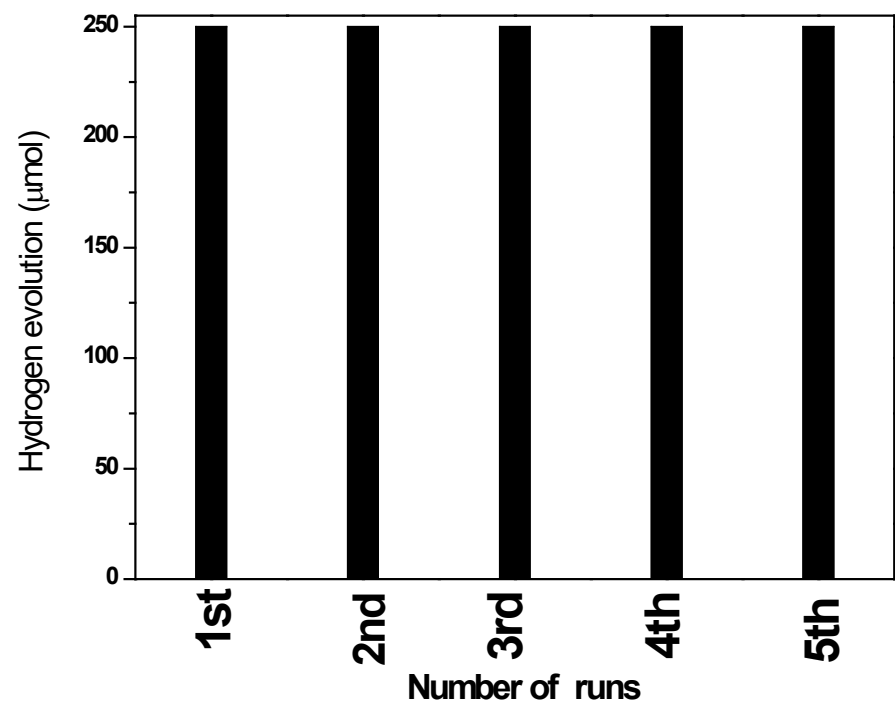

Figure 10. Recycling and reuse of Co/THS photocatalyst on amount of hydrogen evaluation

evaluation. It is clear that $\mathrm{Co} / \mathrm{THS}$ photocatalyst has photocatalytic stability and can be used and recycled many times.

\section{Conclusion}

Titanium dioxide hollow spheres and cobalt/titanium dioxide hollow spheres were prepared by a hydrothermal method in the presence of cyclohexylamine as a surfactant. For comparison purposes, titanium dioxide nanoparticles and cobalt/titanium dioxide nanoparticles were prepared by the same method in absence of surfactant. The hydrothermal method in the presence of a surfactant results in the formation of titanium dioxide hollow spheres and the incorporation of cobalt into titanium dioxide lattice. A red shift is also observed because of the hollow spherical structure and the doping of Co ions. The photocatalytic activity of cobalt/titanium dioxide hollow spheres is better than titanium dioxide hollow spheres, cobalt/titanium dioxide nanoparticles and titanium dioxide nanoparticles for hydrogen production by $1.25,3.3$ and 33.3 times, respectively. Cobalt/titanium 
dioxide hollow spheres show photocatalytic stability for hydrogen production for repetitive use.

\section{Acknowledgment}

This Project was funded by the Deanship of Scientific Research (DSR) at King Abdulaziz University, Jeddah, under grant no. P-11-130436. The authors, therefore, acknowledge with thanks DSR for technical and financial support.

\section{References}

1. Chen J, Qiu F, Xu W, Cao S, Zhu H (2015) Recent progress in enhancing photocatalytic efficiency of $\mathrm{TiO}_{2}$-based materials. Applied Catalysis A: General 495: 131-140.

2. Zhang P, Li A, Gong J (2015) Hollow spherical titanium dioxide nanoparticles for energy and environmental applications. Particuology 22: 13-23.

3. Yadav HM, Kolekar TV, Pawar SH, Kim JS (2016) Enhanced photocatalytic inactivation of bacteria on $\mathrm{Fe}$-containing $\mathrm{TiO}_{2}$ nanoparticles under fluorescent light. $J$ Mater Sci: Mater Electron 27: 4068-4073.

4. Eiden S, Maret G (2002) Preparation and Characterization of Hollow Spheres of Rutile. Journal of Colloid and Interface Science 250: 281-284.

5. Wang D, Song C, Lin Y, Hu Z (2006) Preparation and characterization of $\mathrm{TiO}_{2}$ hollow spheres. Materials Letters 60: 77-80.

6. Lei BX, Zhang P, Qiao HK, Zheng XF, Zhang XX (2014) A facile template-free route for synthesis of anatase $\mathrm{TiO}_{2}$ hollow spheres for dye-sensitized solar cells. Electrochimica Acta 143: 129-134.

7. Zhang Q, Li W, Liu S (2011) Controlled fabrication of nanosized $\mathrm{TiO}_{2}$ hollow sphere particles via acid catalytic hydrolysis/hydrothermal treatment. Powder Technology 212: 145-150.

8. Feng X, Yang L, Liu Y (2010) Preparation of titania hollow spheres by catalyst-free hydrothermal method and their high thermal stabilities. Applied Surface Science 257: 756-761.

9. Lin XP, Song DM, Gu XQ, Zhao YL, Qiang YH (2012) Synthesis of hollow spherical $\mathrm{TiO} 2$ for dye-sensitized solar cells with enhanced performance. Applied Surface Science 263: 816-820.

10. Wang R, Cai X, Shen F (2014) $\mathrm{TiO}_{2}$ hollow microspheres with mesoporous surface: Superior adsorption performance for dye removal. Applied Surface Science 305: 352 358.

11. Ye M, Chen Z, Wang W, Shen J, Ma J (2010) Hydrothermal synthesis of TiO2 hollow microspheres for the photocatalytic degradation of 4-chloronitrobenzene. Journal of Hazardous Materials 184: 612-619.

12. Zhang L, Zhang J, Jiu H, Zhang X, Xu M (2015) Preparation of hollow core/shell $\mathrm{CeO}_{2} @ \mathrm{TiO}_{2}$ with enhanced photocatalytic performance. J Mater Sci 50: 5228-5237.

13. Fang Y, Wang J, Li J, Li L, Lin J, et al. (2016) Preparation and application of black hollow carbon-doped titania composite spheres for electrophoretic displays. J Mater Sci: Mater Electron 27: 6115-6121.

14. Qu X, Yan X, Hou Y, Wang P, Song H (2015) Preparation of Gd-doped TiO2 hollow spheres with enhanced photocatalytic performance. J Sol-Gel Sci Technol (2015) 76: 699-707.

15. Ruiping L, Feng R, Jinlin Y, Weiming S, Zhiming S, et al. (2016) One-step synthesis of hierarchically porous hybrid $\mathrm{TiO}_{2}$ hollow spheres with high photocatalytic activity, Front Mater Sci 10: 15-22.

16. Geng H, Ming H, Ge D, Zheng J, Gu H (2015) Designed fabrication of fluorinedoped carbon coated mesoporous $\mathrm{TiO}_{2}$ hollow spheres for improved lithium storage. Electrochimica Acta 157: 1-7.

17. Zhang Z, Zhou Y, Zhang Y, Sheng X, Xiang S (2013) A spontaneous dissolution approach to carbon coated $\mathrm{TiO}_{2}$ hollow composite spheres with enhanced visible photocatalytic performance. Applied Surface Science 286: 344-350.

18. Cho HJ, Hwang PG, Jung D (2011) Preparation and photocatalytic activity of nitrogendoped TiO2 hollow nanospheres. Journal of Physics and Chemistry of Solids 72: 14621466.

19. Wang Y, Zhu S, Chen X, Tang Y, Wang H (2014) One-step template-free fabrication of mesoporous $\mathrm{ZnO} / \mathrm{TiO}_{2}$ hollow microspheres with enhanced photocatalytic activity. Applied Surface Science 307: 263-271.
20. Tang H, Zhang D, Tang G, Ji X, Yang X (2013) Hydrothermal synthesis and visiblelight photocatalytic activity of a-Fe2O3/TiO2 composite hollow microspheres. Ceramics International 39: 8633-8640.

21. Lv K, Li J, Qing X, Li W, Chen Q (2011) Synthesis and photo-degradation application of WO3/TiO2 hollow spheres. Journal of Hazardous Materials 189: 329-335.

22. Chattopadhyay J, Kim HR, Moon SB, Pak D (2008) Performance of tin doped titania hollow spheres as electrocatalysts for hydrogen and oxygen production in water electrolysis. Int J Hydrogen Energy 33: 3270-3280.

23. Zhang Y, Zhao Z, Chen J, Cheng L, Cao S (2015) C-doped hollow TiO2spheres: In situ synthesis, controlled shell thickness, and superior visible-light photocatalytic activity. Applied catalysis B: Environmental 165: 715-722.

24. Ozbay B, Genc N, Ozbay I, Baghaki B, Zor S (2016) Photocatalytic activities of polyaniline-modified $\mathrm{TiO}_{2}$ and $\mathrm{ZnO}$ under visible light: an experimental and modeling study. Clean Techn Environ Policy 18: 2591-2601.

25. Ameen S, Akhtar MS, Kim YS, Yang OB, Shin HS (2011) An effective nanocomposite of polyaniline and $\mathrm{ZnO}$ :preparation, characterizations, and its photocatalytic activity. Colloid Polym Sci 289: 415-421.

26. Sharma S, Singh S, Khare N (2016) Synthesis of polyaniline/CdS (nanoflowers and nanorods)nanocomposites: a comparative study towards enhanced photocatalytic activity for degradation of organic dye. Colloid Polym Sci 294: 917-926.

27. Min S, Wang F, Han Y (2007) An investigation on synthesis and photocatalytic activity of polyaniline sensitized nanocrystalline $\mathrm{TiO}_{2}$ composites. J Mater Sci 42: 9966-9972.

28. Olad A, Nosrati R (2013) Preparation, characterization, and photocatalytic activity of polyaniline/ZnO nanocomposite. Res Chem Intermed 39: 3969-3979.

29. Cheng Y, An L, Zhao Z, Wang G (2014) Preparation of polyaniline/TiO2 composite nanotubes for photodegradation of AZO dyes. Journal of Wuhan University of Technology-Mater Sci Ed 29: 468-472.

30. Wei J, Zhang Q, Liu Y, Xiong R, Pan C, et al. (2011) Synthesis and photocatalytic activity of polyaniline- $\mathrm{TiO} 2$ composites with bionic nanopapilla structure. $J$ Nanopart Res 13: 3157-3165.

31. Olad A, Behboudi S, Entezami AA (2012) Preparation, characterization and photocatalytic activity of $\mathrm{TiO}_{2}$ /polyaniline core-shell nanocomposite. Bull Mater Sci 35: 801-809.

32. Agarwal S, Tyagi I, Gupta VK, Golbaz F, Golikand AN (2016) Synthesis and characteristics of polyaniline/zirconium oxide conductive nanocomposite for dye adsorption application. Journal of Molecular Liquids 218: 494-498.

33. Patil UV, Ramgir NS, Karmakar N, Bhogale A, Debnath AK, et al. (2015) Room temperature ammonia sensor based on copper nanoparticle intercalated polyaniline nanocomposite thin films. Applied Surface Science 339: 69-74

34. Salvatierra RV, Zitzer G, Savu SA, Alves AP, Zarbin AJG, et al. (2015) Carbon nanotube/polyaniline nanocomposites: Electronic structure, doping level and morphology investigations. Synthetic Metals 203: 16-21.

35. Onn TM, Ramirez LA, Monai M, Soh T, Talati M, et al. (2016) Modification of $\mathrm{Pd} / \mathrm{CeO} 2$ catalyst by Atomic Layer Deposition of $\mathrm{ZrO}_{2}$. Applied Catalysis B: Environmental 197: 280-285.

36. Tang C, Sun B, Sun J, Hong X, Deng Y, et al. (2016) Solid state preparation of NiO$\mathrm{CeO}_{2}$ catalyst for NO reduction. Catal Today 281: 575-582.

37. Kim TH, Seon H, Park DW (2016) Synthesis of $\mathrm{CeO}_{2}$ nanocrystalline powders using DC non-transferred thermal plasma at atmospheric pressure. J Sol-Gel Sci Technol 27 2012-2018.

Copyright: (C2019 Mohamed RM. This is an open-access article distributed under the terms of the Creative Commons Attribution License, which permits unrestricted use, distribution, and reproduction in any medium, provided the original author and source are credited. 